\title{
Preface for the Special Themed Issues
}

DOI: $10.1134 / \mathrm{S} 1068162015060138$

The VIIth All-Russian "Proteins and Peptides" Symposium organized by the Institute of Chemical Biology and Fundamental Medicine of the Siberian Branch of the Russian Academy of Sciences (RAS), Shemyakin and Ovchinnikov Institute of Bioorganic Chemistry of the RAS, Biological Sciences Division of the RAS, and the Bioorganic Chemistry Research Council of the RAS, was held in Novosibirsk, July 12-17, 2015. The program of the Symposium included 18 plenary lectures by leading researchers, 93 oral presentations, and 152 poster presentations. The number of Symposium participants was over 300 .

Similarly to the previous years, presentations made at the symposium encompassed an extremely broad range of research objects, goals, and methods. The themes addressed at the symposium included the following:

1. Methods of fractionation, purification, and primary structure analysis. Isolation of novel research objects from natural sources. Peptidomics. Proteomics.

2. Synthesis methods, chemical modification. Protein engineering.

3. Physicochemical and computational research methods. Spatial structure.

4. Biological activity. Structure-function relationships.
5. Enzyme chemistry and biology.

6. Innovative pharmaceuticals based on peptides and proteins, and mechanisms underlying their action.

A special session was dedicated to the structure and function of proteins involved in the regulation of programmed cell death. Research presented at the symposium had been performed in numerous research centers in Russia, including RAS institutes, universities, and institutes of the healthcare system. Scientists from Belorussia presented their results along with Russian researchers, and a number of studies were performed in collaboration with scientists from Europe and the United States of America.

Reports of studies presented at the Novosibirsk symposium (a total of 27 articles) will be published in the upcoming issues of our Journal. These studies form only a small part of the research presented; however, we believe that the selection provides useful information on the diverse research topics, results and level of the studies, and the geographical location of the major centers of protein and peptide chemistry and biology research in Russia.

Academician V.T. Ivanov, Editor-in-Chief Translated by S. Semenova 